\title{
Lymphatic Filariasis in India: A Journey towards Elimination
}

\author{
Srivastava Pradeep Kumar
}

Former Joint Director, NVBDCP, 22 Sham Nath Marg, Delhi, India.

DOI: https://doi.org/10.24321/0019.5138.202024

\section{I $\quad \mathbf{N} \quad \mathbf{F} \quad \mathbf{O}$}

E-mail Id:

pkmalaria@yahoo.co.in

Orcid Id:

https://orcid.org/0000-0002-7696-3845

How to cite this article:

Kumar SP. Lymphatic Filariasis in India: A Journey towards Elimination. J Commun Dis 2020; 52(3): 17-21.

Date of Submission: 2020-03-12

Date of Acceptance: 2019-04-15

\section{$\begin{array}{llllllll}\mathbf{A} & \mathbf{B} & \mathbf{S} & \mathbf{T} & \mathbf{R} & \mathbf{A} & \mathbf{C} & \mathbf{T}\end{array}$}

The journey towards elimination of Lymphatic Filariasis (ELF) in India started with the deliberations in a meeting held at Delhi in 1996 recommending for pilot project of Mass Drug Administration (MDA) with DEC. Global Programme to Eliminate Lymphatic Filariasis (GPELF was launched in 2000 subsequent to World Health Assembly (WHA) resolution in 1997 making India as signatory. ELF campaign was launched on $5^{\text {th }}$ June, 2004 with annual MDA in endemic districts. However, all the endemic districts could not initiate MDA due to logistics and preparedness issues, thus the journey initially experienced challenges of hurried start. Serious Adverse Events (SAE) and poor compliance were reported from many states which were tackled through advocacy and capacity building of health workers and community volunteers. MDA was managed with staggering of dates in different states and strong supervision helped in improving drug compliance. The improved reported drug coverage resulted in decline of microfilaria prevalence in many districts except some districts. India's significant progress was recognised internationally as approximately 200 of 650 million population at risk of Lymphatic Filariasis (LF) was made free of risk by 2017 by passing Transmission Assessment Survey (TAS) though some districts could not clear TAS. Efforts to improve drug compliance were intensified and to achieve goal faster, MDA with three drug Ivermectin, DEC and Albendazole has been initiated in addition to ascertaining the current status of LF endemicity in non-MDA districts. Based on experience of long journey towards ELF with mix of success and challenges, it is suggested to intensify ELF in a mission mode with priority.

Keywords: ELF, MDA, TAS, LF

\section{Introduction}

LF is a seriously debilitating and incapacitating disease. The infected person remains apparently healthy during early phase of infection, but serves as a source of infection for transmission. This stage may continue for 5-7 years and can be treated with microfilaricidal drug when detected. ${ }^{1}$
South East Asia (SEA) region accounts for the highest burden of LF among the six World Health Organization (WHO) regions. All the three lymphatic filarial parasites, namely Wuchereria bancrofti, Brugia malayi, and Brugia timori are prevalent in the region but $W$. bancrofti accounts for $95 \%$ of the infections. Of the 1.3 billion people globally at risk of 
LF, 850 million reside in SEA and of the 120 million globally infected people, 60 million are in the region. The region thus accounts for $65 \%$ of the global population at risk and $50 \%$ of the infected people. The achievement of the LF elimination in SEA will therefore have a big impact on the reduction of the global burden. ${ }^{2}$ The nine LF endemic countries of SouthEast Asia Region (SEAR) are Bangladesh, India, Indonesia, Maldives, Myanmar, Nepal, Sri Lanka, Thailand and Timor Leste which have undertaken the implementation of GPELF. The two non-endemic countries are Bhutan and Democratic People's Republic of Korea (DPR). In mainland of India, the most predominant causative organism for filaria infection is Wuchereria bancrofti which is transmitted by the vector, Culex quinquefasciatus. ${ }^{3}$ Bancroftian infection contributes to 99.4\% of the LF problem in the country which is endemic in 21 states and Union Territories. The bancroftian infection is prevalent in both urban and rural areas. B. malayi infection, earlier mainly restricted to rural areas of six states, is now reported only in one district of Kerala and recently one district of Odisha. Mansonia annulifera is the principal vector while $\mathrm{Ma}$. (Ma). uniformis and $\mathrm{Ma}$. (Ma) indiana are the secondary vectors for transmission of $B$. malayi infection. The nocturnal periodicity of microfilaremia by both $W$. bancrofti and $B$. malayi infections are known in mainland of India. The diurnal subperiodic $W$. bancrofti infection was discovered in 1974-75, ${ }^{4}$ among aborigines inhabiting Nicobar Group of Andaman \& Nicobar Islands. Ochlerotatus (Aedes) niveus group of mosquitoes were incriminated as the vectors for $W$. bancrofti.

The journey towards ELF in India started with the deliberations in a meeting held at Delhi in 1996. Revised strategy for control of LF in India was deliberated in a workshop ${ }^{5}$ held at National Institute of Communicable Diseases (now known as National Centre for Disease Control) and National Malaria Eradication Programme (now known as National Vector Borne Diseases Control Programme). Consequently, MDA with DEC on a pilot was initiated during 1996-97. The first district to observe MDA on $5^{\text {th }}$ August 1996 was South Arcot (now Cuddalore) in Tamil Nadu. Later, the trial was extended to 13 districts in seven states. Since the year 2000, a study with DEC and DEC + Albendazole was undertaken to study the feasibility and impact of co administration versus DEC alone. Meanwhile, the International Task Force for Disease Eradication identified LF as one of the six infectious diseases to be "eradicable" or "potentially eradicable and World Health Assembly (WHA) ${ }^{6}$ passed the resolution in 1997 for Elimination of LF (ELF) ${ }^{7}$ as a global public health problem by 2020 . India became a signatory to this resolution and the commitment towards elimination started. First meeting of Global Alliance to Eliminate LF (GAELF) was convened at Santiago de Compostela, Spain on 4-5 May 2000 and Indian Health Secretary while chairing the session stated, "it would be a long haul for India and that interim target dates would be necessary between now and the year 2020."National Health Policy ${ }^{8} 2002$ of Indiathus envisaged the elimination by 2015 ( 5 years ahead of global goal) but this could not be achieved in spite of phenomenal success and remained as interim target which later has been aligned with global target of ELF by 2020. The two main objectives of GPELF ${ }^{9}$ launched in 2000 were as mentioned below:

- To progressively reduce and ultimately interrupt the transmission of lymphatic filariasis.

- To prevent and reduce disability in affected persons through disability alleviation and appropriate management.

\section{Strategy of Elimination of LF}

The strategy for ELF is based on following two pillars:

- Annual MDA of single dose of DEC (Diethylcarbamazine citrate) for 5 years or more to the eligible population (except pregnant women, children below 2 years of age and seriously ill persons) to interrupt transmission of the disease.

- Home based management of lymphoedema cases and up-scaling of hydrocele operations in identified Community Health Centers (CHCs)/ District hospitals/ medical colleges.

\section{Programme Implementation in India}

To realize the goal set for LF elimination in India, it was decided in the year 2003 to cover all endemic districts under elimination strategy and the endemic districts were identified based on the available data generated under programme as well as by the research institutions. ELF campaign after technical consultations with all endemic states/ Union Territories was launched in the year 2004 by starting annual MDA duly inaugurated by the then Union health minister and Union minister of health for State in Thane and Rae Bareli simultaneously. The operational guidelines ${ }^{10,11}$ and training manuals were framed and disseminated across various states and UTs. The National Filaria day was decided as $5^{\text {th }}$ June but all the districts identified could not initiate MDA as probably more preparatory time for states was required with adequate logistics of drugs and finance. Only 202 districts could be covered that too in June, July and September. The cruising time for programme to mature had many challenging experiences but continued ahead with ambitious plan. Many places reported SAE and even deaths occurred on the day of MDA were linked with DEC which, were later proved to be otherwise. Based on the experience of MDA in 2004 during hot month of June, the date of National Filaria day with consensus of states was changed to 11 November. The launch of MDA was organized in a big way at Hyderabad with Union health ministers, state health ministers, Chief 
Secretary, secretary health of state, programme Director and programme officers swallowing tablets in front of more than thousand people giving a great momentum to the programme.

Every endemic state and districts were covered under national training campaign in 2005-2006 with the help of WHO, ICMR and National Centre for Disease Control (NCDC). Faculties of 79 medical colleges were oriented on national policy of MDA and concept of ELF. Number of districts brought under MDA were 243 but MDA could not be implemented in 14 districts of Tamil Nadu due to unprecedented rains and flood. However, mortality reported after consuming DEC in some cases at Trichy district of Tamil Nadu were also one of the reasons for non-observance of MDA.

While the programme was being upscaled, decisions on replacement of loose DEC tablets with strip packing and co administration of Albendazole with DEC were taken during 2006. However, it is pertinent to mention that neither could WHO supply Albendazole required nor DEC in strip packing was made available in time which forced in managing staggered MDA and also non-observance of MDA in five states. Only 196 districts could observe MDA against targeted 243 districts. During 2007, all the 250 identified LF endemic districts were brought under MDA but DEC + Albendazole was administered only in Tamil Nadu and Kerala. In 2008, two-drug administration was extended to four southern states whereas rest of the districts had MDA with DEC alone ${ }^{12}$ except 38 districts of Bihar where MDA round was missed.

Though the observance of MDA was losing its priority and some or the other states were missing MDA, many districts started reporting improved drug coverage and significant reduction in $\mathrm{mf}$ prevalence. Home based morbidity management ${ }^{13,14}$ was also scaled up and mostly line-listing of lymphoedema and hydrocele cases was made in all endemic districts enumerating around 1.3 million cases. The national average of $\mathrm{mf}$ prevalence dropped from 1.3 per cent to 0.4 percent by 2016 and out of 256 endemic districts, about 200 districts reported average mf prevalence below $1 \%{ }^{15,16}$ This significant achievement was subjected to independent appraisal and assessment by Joint Monitoring Mission. In addition, every year the post MDA assessment by medical colleges, regional offices and research institutions was undertaken which was made as inbuilt component of programme, though some states could not get it done due to resource constraints both physical and financial.

The monitoring and independent assessment of programme performance were being documented with mix of recommendations mainly emphasizing to improve drug compliance, besides strengthening IEC/ BCC activities, intensification of morbidity management, quality check and assurance of microfilaria survey and taking cognisance of reports on certain LF endemic foci in districts which were reportedly non-endemic.

Though most of the states showed improvement and broadly achieved the target which required further assessment for transmission threshold to facilitate the decision to continue or discontinue MDA. The WHO guidelines of "Monitoring and epidemiological assessment of the programme to eliminate LF at implementation unit level-2005"17 was revised in 2011 to provide clearer and more feasible methodologies to national programmes on monitoring and epidemiological assessment ${ }^{18}$ and evaluation in order to achieve global target of eliminating LF by 2020 . This revised guidelines on monitoring and evaluation and WHO document on strategic plan ${ }^{19}$ since then has been used in programme for Transmission Assessment Survey (TAS). There were series of training workshops at national and subnational level on TAS and the national guidelines on TAS $^{20,21}$ were circulated to states.

Indian programme on LF elimination started tasting the success ${ }^{22}$ when Goa, Thiruvarur of Tamil Nadu and Daman Diu passed first TAS during 2013-14. There were many success stories as many districts ${ }^{23}$ started reporting microfilaria prevalence below $1 \%$ and cleared TAS successfully.

\section{Discussions and Conclusion}

Considering the magnitude of problem, requirement of logistics and progress made towards LF elimination, the Indian programme had global appreciation as reducing about 200 million out of more than 650 million population from risk of LF which had significant impact on global burden. However, the main challenge was how to achieve the elimination goal in set period. The key to success is actual drug compliance as observed and recommended with documentary evidence in community based trial ${ }^{24}$ and different evaluation studies. ${ }^{25-37}$ Considering the reports and recommendations made in published documents, all states and UTs were emphasized to take massive efforts in order to improve drug compliance along with strict supervision and monitoring. To realize the goal in next 2-3 years, third drug i.e. Ivermectin was added with DEC and Albendazole but it started only in few districts and expected to be extended in other hard-core districts sooner.

The long journey towards ELF with significant success and many challenges due to varying performance of service providers and response of community in different regions has flagged various issues. One of the most crucial issues is the need to sustain achievements made so far and intensify ELF in mission mode need to be considered if it is to be made within specified period. Secondly, the current status of LF endemicity in reportedly non-MDA districts ${ }^{38}$ 
and liquidating foci with treatment and entomological monitoring ${ }^{39,40}$ for vector control are also current priority and need to be ascertained. The morbidity management and disability alleviation (MMDP) need to be geared up as it has become one of the important components of dossier for certification of elimination and the minimum requirement is one MMDP centre per district to provide services to community.

\section{Acknowledgement}

The ELF programme in India is one of the largest public health programmes as it targets to cover approximately 650 million population on one day for MDA which has more or less been accomplished with the help of endemic states which are implementing agencies. Their efforts are greatly acknowledged during the journey of ELF.

\section{Conflicts of Interest: None}

\section{References}

1. Sasa M. In: Human filariasis: A global survey of epidemiology and control. University of Tokyo 1976, 819.

2. WHO. Lymphatic Filariasis Infection \& Disease: Control Strategies. Report of a Consultative Meeting held at University Sains Malaysia, Penang, Malaysia. 1994.

3. Sharma RS. National Filaria Control Programme, Operational Manual. National Malaria Eradication Programme, Delhi. 1995.

4. Kalra NL. Filariasis among the aborigines of Andaman and Nicobar Islands. J Commun Dis 1974; 6: 40-56.

5. Biswas G. Revised strategy for the control of lymphatic filariasis in India, New Delhi. National Institute of Communicable diseases and National Malaria Eradication program, Delhi. 1996.

6. WHA. ELF as a public health problem. Resolutions and Decisions. 1997; 27-28.

7. Ottesen EA, Duke BOL, Karam M et al. Strategies and tools for the control/ELF. Bulletin of WHO 1997; 75(6): 491-503.

8. National Health Policy. Ministry of Health and Family Welfare, Government of India, New Delhi. 2002; 1-39.

9. Ottessen EA. The global programme to eliminate Iymphatic filariasis. Trop Med Int HIth 2000; 5: 591-594.

10. National Vector Borne Disease Control Programme. Operational Guidelines on Elimination of lymphatic filariasis, India. Directorate of National Vector Borne Disease Control. 2005.

11. National Vector Borne Disease Control Programme. Operational Guidelines on Elimination of Iymphatic filariasis, India. Directorate of National Vector Borne Disease Control. 2009.

12. Srivastava PK, Dhillon GP. Elimination of Iymphatic filariasis in India - a successful endeavour. J Indian
Med Assoc 2008; 106: 673-674, 676-677.

13. World Health Organization. Lymphatic filariasis: progress of disability prevention activities. Weekly Epidemiological Record 2004; 79: 417-424.

14. Srivastava PK, Dhariwal AC. Progress towards morbidity management under elimination of lymphatic filariasis programme in India. J Indian Med Assn 2010; 108 (12): 854-862.

15. Srivastava PK, Dhariwal AC, Bhattacharjee J. Status of LF in India. Health Action 2013; 19.

16. Srivastava PK, Bhattacharjee J, Dhariwal AC et al. Elimination of lymphatic filariasis - Current status and way ahead. J Commun Dis 2014; 46: 85-94.

17. World Health Organization. Monitoring and epidemiological assessment of the programme to eliminate lymphatic filariasis at implementation unit level. 2005.

18. World Health Organization. Global programme to eliminate lymphatic filariasis: monitoring and epidemiological assessment of mass drug administration-TAS. 2011.

19. World Health Organization. Global programme to eliminate lymphatic filariasis. Progress report 20002009 and Strategic plan 2010-2020. 2010.

20. National Vector Borne Disease Control Programme. National Guidelines for Transmission Assessment Survey. 2013. Available from: https://nvbdcp. gov.in/WriteReadData/1892s/TAS-NationalGuidelines-2013-14.pdf.

21. Srivastava PK, Sharma SN, Bhattacharjee J, et al. A Tool for Monitoring epidemiological impact of mass drug administration (MDA) in the ELF- an Indian experience. J Commun Dis 2014; 46(2): 1-6.

22. Srivastava PK, Krishnamoorthy K., Govenkar S, et al. Elimination of lymphatic filariasis in Goa: first successful transmission assessment survey in India. J Commun Dis 2014; 46(2): 7-16.

23. Dhariwal AC, Srivastava PK, Bhattacharjee J. Elimination of lymphatic filariasis in India: an update. Journ Indian Med Assn 2015; 113(12): 189-190.

24. Boyd A, Won KY, McClintock SK et al. A communitybased study of factors associated with continuing transmission of LF in Leogane, Haiti. PLoS Negl Trop Dis 2010; 4: e640.

25. Cantey PT. Predictors of compliance with a mass drug administration programme for lymphatic filariasis in Orissa State, India. Trop Med Int Health 2008; 15: 224-231.

26. Kumar A, Kumar P, Nagaraj K et al. A study on coverage and compliance of mass drug administration programme for elimination of filariasis in Udupi district, Karnataka, India. J Vector Borne Dis 2009; 46: 237-240.

27. Kumar P, Prajapati PB, Saxena D et al. An evaluation of 
coverage and compliance of mass drug administration 2006 for elimination of lymphatic filariasis in endemic areas of Gujarat, India. J Commun Med 2008; 33: 38-42.

28. Lahariya C, Mishra A. Strengthening of mass drug administration implementation is required to eliminate lymphatic filariasis from India: an evaluation study. $J$ Vector Borne Dis 2008; 45: 313-320.

29. Mukhopadhyay AK, Patnaik SK. Effect of mass drug administration programme on microfilaria carriers in East Godavari district of Andhra Pradesh. J Vector Borne Dis 2007; 44: 277-280.

30. Mukhopadhyay AK, Patnaik SK, SatyaBabu P et al. Knowledge on lymphatic filariasis and mass drug administration (MDA) programme in filaria endemic districts of Andhra Pradesh. J Vector Borne Dis 2008; 45: 73-75.

31. Mukhopadhyay AK. Lymphatic filariasis in Andhra Pradesh Paper Mill Colony, Rajahmundry, India after nine rounds of MDA programme. J Vector Borne Dis 2010; 47: 55-57.

32. Ramaiah KD, Vanamail P, Das PK. Changes in Wuchereria bancrofti infection in a highly endemic community following 10 rounds of mass administration of diethylcarbamazine. Trans R Soc Trop Med Hyg 2007; 101: 250-255.

33. Regu K. Mass drug administration against lymphatic filariasis: experiences from Kozhikode district of Kerala State. J Commun Dis 2006; 38: 333-338.

34. Showkath Ali MK, Regu K, Rajendran R et al. Awareness of health personnel about lymphatic filariasis and MDA in Kerala state. J Commun Dis 2008; 40: 37-40.

35. Swaminathan S, Perumal V, Adinarayanan S. Epidemiological assessment of eight rounds of mass drug administration for lymphatic filariasis in India: implications for monitoring and evaluation. PLoS Negl Trop Dis 2012; 6(11): e1926.

36. Vaishnav KG, Patel IC. Independent assessment of mass drug administration in filariasis affected Surat city. $J$ Commun Dis 2006; 38: 149-154.

37. Vaishnav KG, Desai HS, Srivastava PK et al. Impact of mass drug administration on elimination of lymphatic filariasis in Surat city, India. J Commun Dis 2012; 44(4): 251-259.

38. Khan AM, Dutta P, Khan SA, et al. Prevalence of bancroftian filariasis in a foothill tea garden of upper Assam. J Commun Dis 1999; 31: 145.

39. Das PK, Ramiah KD. Entomological monitoring of annual mass drug administration for the control or elimination of lymphatic filariasis. Annals of Tropical Medicine \& Parasitology 2002; 96(20) S142.

40. World Health Organization. Lymphatic Filariasis: Practical Entomology A Hand-book for National Elimination Programmes. 2013. Available from: http://apps.who. int/iris/bitstream/10665/87989/1/9789241505642_ eng.pdf?ua=1. 